\title{
Higher Education Provision Using Systems Thinking Approach - Case Studies
}

The purpose of this paper is to highlight the complexities involved in higher education provision and how systems thinking and sociotechnical systems (STS) thinking approach can be used to understand the education ecosystem. Systems thinking perspective is provided using two case studies: the development of European Learner Mobility (EuroLM) service and the delivery of Enterprise System Management (ESM) course at the Birmingham City University, UK. The case studies present how systems thinking using STS approaches like applied organisational change and Cognitive Work Analysis can be used to capture a conceptual model of the education system for understanding the interactions and relationships between the people, technology, processes and the organisations. Using systems thinking perspective, EuroLM has developed a set of technical standards addressed to the European systems developers and ESM delivery ensures that students communicate and collaborate.

Keywords: Socio-Technical Systems (STS) thinking, European Learner Mobility (ELM); Cognitive Work Analysis; Higher Education Provision; Enterprise System Management delivery.

\section{Introduction}

Education is a complex ecosystem that has evolved for over 1000 years including the recent change from passive to active learning strategies such as project-based learning, problem-based learning, inquiry-based learning, design-based learning and further (Barak and Williams 2007). Technology has been a major driver of change triggering significant reforms in several parts of the System. The current functioning of the education system can be seen as an elaborate "interwoven tapestry of finest legacy threads together with numerous patched weavings in the $20^{\text {th }}$ and $21^{\text {st }}$ centuries" (R. Larson, MIT, 2014, page - 153). However, the "patch" approach has reached its limitations. Reconceptualization and integration of emerging technology constituents are critical towards a new holistic thinking and design through a systems thinking (Trist 1950) lens that allows the consideration of changing political climate, market condition, financial pressure, competency, public awareness, and technology.

Systems thinking design approach comprises of a technical level (hardware and software), a human level (stakeholders, maintenance agents, operators, designers) and an organisational level (a set of rules, policies, interactions governing different actions, and more) (Belmonte et al 2011; Sommerville et al 2012; Long 2013). Socio-technical systems (STS) (Cooper and Foster 1971) design approach have been applied for many years in complex domains such as transportation, military, and healthcare. For example, civil aviation which is a complex public transportation system comprising of several technological artefacts like: aircrafts, runways, communication systems, luggage transport systems, etc. with various interconnections and relationships between the technical artefacts and the socio-organisational environment constituting of various policies, human agents and behaviour. Thus functioning of civil aviation is not purely 
on the functioning of the technical artefacts, all the artefacts play an essential role in the functioning of the transport systems as a whole (Kroes et al. 2006).

Systems approach is needed as the education system is not a simple, isolated system: the action of individuals, technology and social practices bleed-in to education from general civil life (Cooper 2010). Education system has inextricable binding into the social, political, organisational, technical and economic structures and collective intentions, combining elements of control, choice and autonomy, suggests that it should be considered using STS perspective. Likewise to overcome the complexities in education, systems thinking approach would help in conceptual modelling of the education and learning space, including: actors, processes, artefacts, technology, interactions (internal and with external agents), organisational policies and communication systems. The "transitional" and dynamic qualities of conceptual models provide a key to understanding the domain (Hoel and Pawlowski 2011) and progressively work on the scaffolding of inherent complex structures of the higher education ecosystem. Models allow dealing with system complexity and adaptivity the idea that agents in the system interact and evolve according to their environment and consequently change the nature of the system.

A quite interesting paradigm of this approach is the design, development and evolution of Learning Technology standards. Learning technology is a young concept at the intersection of the complex social enterprise of education and the rapid change of technology. In this field European and International standardization on ICT for Learning, Education and Training (ICT LET,) is committed to establishing harmonized frameworks, which embody wide stakeholder community commonalities that can be expanded upon at national, regional or even global levels.

Standardization processes follow the STS thinking since they are bound to provide a conceptual view of the ecosystem and their interactions including the need for the system, its requirements, specifications, guidelines or characteristics that can be used consistently to ensure that materials, products, processes and services are fit for their purpose (ISO 2014) and define common specifications and/or procedures to respond to the needs of business and meet consumer expectations (CEN 2014). On this basis, ICT LET standards are developed:

- to respond to the internal system requirements while at the same time focusing on and facilitating the implementation of a business strategy to interact with its multifaceted environment;

- to accommodate diversity and change and to be part of the systemic processes from which learning technology emerges; and

- in a layered and modular style with core semantic units as the stable foundation

This paper highlights that education provision is a complex ecosystem composed of various components (including software, hardware, people, organisation, and regulations) nested within subs levels (including programming software, computer networks, staffs, students, partners, ownerships, and policies) which are interconnected with each other and any change in one system will ripple through and influence others leading to various complexities leading to: mismatch of competencies to needs; less interdisciplinary or multidisciplinary teamwork; education dominance; labour market imbalances and much more. To breakdown the complexities this paper provides two case studies to show how education ecosystem can be better conceptualized and modelled through socio-technical systems perspective that includes technical systems, 
operational processes and the people who use and interact with the systems governed by organisational policies.

\section{Complexity in Higher Education Provision}

Higher education (HE) has evolved over the years impacted by external and internal factors. The external factors especially in the developed countries are due to the revolution of new skills based on government policies and industrial demands, forcing the higher education institutes to move away from reliance on traditional public sector finances and models to privatized, commercialized and self-sustain models. This has impacted the internal approaches and the strategic vision and mission of HE institution, from traditional delivery approaches of face-to-face and class room to a complex and dynamic methods of delivery including off-line, distance, partnership and franchise models using up to date technology, across the globe to increase their market share. Therefore Higher education provision is a complex ecosystem or systems that constitutes various components or layers including (Figure 1)

- Hardware: includes computers, projectors and devices associated with the machines and equipment.

- Software: includes the software needed for HE provision like the operating system and programming languages.

- People and their roles: constitutes all the stakeholders in the system including students, lecturers, admin and their roles in the system.

- Delivery: specifies the method of course delivery for the students within faceto-face or online learning environments.

- Management and Procedures: management models and procedures required for the higher education provision like the financing, reporting, delivery.

- Organisation and Regulators: includes high level strategic business activities that may affect the operation of the education system like the market conditions, financial pressure, ownership and affiliations.

- Government: The requirements for higher education provision including the laws and regulations.

The following table presents some of components in HE in a schematic form.

\section{[FIGURE 1 ABOUT HERE]}

As higher education systems comprises of complex relationships that are constituted by highly disparate interactions among people, economies, government structures, laws, ethics, cultural norms, software and hardware (Gattie et al., 2011) .Solutions for HE provision tend to be modelled using either sequential and epidemiological approaches or technology-centred and human-centred approaches. For instance, standard software engineering or technology-centred approaches can be used for the education provision but they mainly focus on the hardware, software, procedures, and rules that are needed 
to successfully meet the HE provision requirements. People and their roles are mostly considered to understand the explicit interactions people would have on the system and their roles or hierarchy in the system. Alternatively, systems engineering and humancentred approaches can be used in addition to the standard software engineering approach, as this approach considers most of the layers shown in Figure 1 that is the people, organisation, business processes and the equipment needed for achieving the business requirements.

These standard engineering approaches or technology-centred and human-centred approaches could be useful for understanding and delivering higher education systems; however, they are not successful in addressing or capturing the complexities in a higher education ecosystem (Qureshi 2007). However, the highly desperate interactions with the environment in HE are somewhat more complex consisting: desired (intentional) interactions and spurious (unintentional) interactions (Rompelman 2006) which can be overlooked in standard approaches.

Therefore complexity of an education ecosystem poses a challenging interrelationship or dependency in various layers (Figure 1) involving the software and hardware, government, organisation, management policies and people. For example, the delivery of a course is not just dependent on the staff or hardware or software. It comprises of various components including: technical level (hardware and software), a human level (people, management, staff, partners and students), organisational level and much more. Although Figure 1 represents each layer as a separate level, independent of the other layers, in reality layers may be interrelated in numerous ways which can influence the behaviour of the system. For instance, the method of course delivery is dependent on the software, which in turn is dependent on the available hardware that is decided by the people taking into consideration all the organisational policies and procedures and the government laws and regulations. Any change in the organisational or government or the management will ripple through and affect the delivery of the course and student satisfaction. Therefore the properties and behaviour of the each of the components in Figure 1 are inextricably inter-mingled leading to various complexities such as:

Structural complexity: The system is composed of various interconnected levels and subs levels interacting between them and the external environment.

Behavioural complexity: Where each level or sub-levels perform multiple roles and behaviours that circumscribe the requisite variety implied by an organisational or procedural context (Denison, Hooijberg, \& Quinn, 1995), such as people, industry and their competitive demands. 
These complexities in the system could lead to: mismatch of competencies to needs; less interdisciplinary or multidisciplinary teamwork; education dominance; labour market imbalances and much more. For instance, current European policies on "New Skills for New Jobs" (EC 2008) greatly affect the organisational and marketing plans of the institutions, because of the implied strategic priority to re-design their educational offerings in accordance with industry needs. On this basis, a university may plan to adopt a dual educational system (offer courses in partnership with industry) which may also affect the course delivery choices. This change might also reflect in changes in procedure (e.g. management models, financing, reporting delivery), the organisation (e.g. ownership) and software (e.g. applications and programming languages). This implies that there is a need to understand the education ecosystem including: people and their role in the system, scale and scope of the system, technology requirements, systems functionality, and the interactions or interrelationships between the technical, human, social and organisational aspects of the system (Qureshi 2007) through STS thinking. Thus, there is a compelling need to capture the complexity of education ecosystem to provide a broad systemic view for understanding the various interactions, links and dependencies from a multi-dimensional aspect for better conceptualization and modelling of the complex education systems.

\section{Systems Thinking Design Approach}

This section provides two case studies to show how systems approach can be used to capture a conceptual model of the education system for understanding the interactions and relationships between the people, technology, processes and the organisations. The first case study shows the development of European Learner Mobility (ELM) service and the second case study deals with the implementation of the Enterprise System Management (ESM) course at the Birmingham City University, United Kingdom along with a preliminary feedback from the students on the effectiveness of delivery.

\subsection{Case Study 1: EuroLM}

The enhancement of learner mobility and employability is a high priority action item within the Europe. European Union (EU) has already set up the processes for transforming European education in a 'world quality reference'. The fulfilment of this ambitious goal involves the development and adoption of instruments for the expression of the European citizens' learning, training and employment related to information across the entire European Education Area.

The field of European Learner Mobility and the new European dimensions in LET require the development of interoperable information services for the facilitation of emerging practice, including the support of new mobility schemes, trans-national programs of study, inter-institutional cooperation, exchanges between institutions and employers, advanced learner personal organisation and development (e-portfolio tools and documents), etc. The CEN European Learner Mobility (EuroLM) standardization working item, concluded in 2010 (EuroLMAI 2010), has had as main objective the provision of data models, specifications and guidelines for the expression and exchange 
of learner mobility information, which is either explicitly defined at an European policy level and captured in the European transparency instruments, or that directly emanates from current learning, education and training practice and processes in Europe. As perceived within the context of the project, EuroLM follows two parallel, yet equally important standardization paths: one that directly addresses the European requirement for rapid implementation and dissemination of the transparency information tools throughout Europe to enhance mobility; while the other focuses on sketching the broader mobility landscape, thus providing the vision and preparing the ground for further development, augmentation and exploitation of transparency information that will lead to the emergence of valuable services to the community (e-portfolio, learning and employment opportunity exploration, etc.).

One of the key starting points of the overall process has been the identification and representation of the learner mobility setting and practice. According to the STS approach, the domain modelling has been based on constituents including policy context (laws and regulations), people (stakeholders), processes (business cases), software services and information models (data structures). The resulting diagrammatic representation (Figure 2) has been a roadmap for planning and action, revealing the key aspects in building coherent ICT standards for learner mobility that correspond to stakeholder and wider environment requirements.

First, European and National policy stakeholders — as the main initiators and promoters of European and cross-cultural and trans-national learning, education and training (LET) policies and instruments - could be imagined as being above the diagram, looking down at the whole. They are represented here looking in from all sides of the diagram.

Second, there are the three other stakeholder groups: (1) Learners, (2) Employers, and (3) LET organisations offering learning, education, and training opportunities. Each of these three stakeholder groups organizes their information about LET around particular concepts that are useful to them: these are the arrows near the three sides of the diagram. In practice, this information is organized into structured sets: these are the boxes in the areas marked "Information Models." Some of these sets of information have agreed specifications of their electronic representation, some at present only have paper formats, which may or may not be generally agreed or standardized. The information models shown are only illustrative: on the employers' side, in particular, there are many more.

\section{[FIGURE 2 ABOUT HERE]}

Third, there are the Developers and Implementers as additional stakeholders that may attempt to develop and offer services that are related to learner mobility in some way. Some of these services are shown in ovals within the central "Services" rectangle. In this broad view, services relevant to learner mobility range from those helping learners choose LET opportunities, and those related to the administration processes involved in taking up learning opportunities, through services relevant to LET itself, to services relevant to helping learners secure desired employment.

Lastly, it is the role of European standardization organisations, in consensus, to assemble the standards and specifications, to be used by developers and implementers, 
to build interoperable tools and services that help satisfy the needs of the other stakeholder groups. Instead of standardizing long and inflexible information models, the standardization of small information entities offers a modular approach promoting reuse of base information schemes in larger models. These "building block" standards and specifications can then be mixed-and-matched in larger information models to cover specific needs and drive the implementation of European-wide Services. The standardization organisations themselves are also, like the policy stakeholders, not shown, as they should ideally have an overview of the complete picture, so that the standards and specifications produced or adopted can be optimally adapted for reuse across, and even beyond, the field of learner mobility.

\subsubsection{Systems Perspective}

For understanding and analysing the ecosystem, system perspectives involved gathering relevant data from appropriate sources including (stakeholders, subject matter experts, documents and internal and external actors) using an iterative process. Table 1 shows, for example, the various stages along with the functions that required data and information collection for the course/curriculum lifecycle (JISC 2013).

[TABLE 1 ABOUT HERE]

Our systems perspective is based on the framework developed by Leavitt and March (1965) on applied organisational change and others (Morton 1991; Handy 1993; Davis et al. 2014) which is focused on the relationships between people (stakeholders), tasks, processes and technologies. In the following sections, the EuroLM system constituents are analysed in detail. The EuroLM case builds upon the 'Guidelines on a EuroLM model' carried out within the European Standardization Committee (CEN WSLT 2010).

\section{i. Policy context (laws and regulations)}

EU member states and the European Commission have in recent years strengthened their political cooperation through the Education and Training 2010 work programme, followed up by the strategic framework for European cooperation in Education and Training ET 2020 (EC 2009). They integrate previous actions in the fields of education and training at the European level, including vocational education and training under the Copenhagen Process, and links up to the Bologna Process, which is crucial in the development of the European Higher Education Area (EHEA). Strategic objective 1 of the ET 2020 framework is "Making lifelong learning and mobility a reality".

The Education and Culture DG sets out a "European strategy and co-operation in education and training" whose objectives are:

- improving the quality and effectiveness of education and training systems

- facilitating access to education and training systems

- opening up EU education and training systems to the wider world

- raising awareness on European policies 
- better dissemination and exploitation of the Europass (European Parliament and the Council 2004), transparency documents

- implementation of Bologna processes

\section{ii. Organisational Procedures and Policies}

Within the wider policy context, specific policies, priorities and procedures are defined, at different organisational levels, to guide and foment the implementation of ELM activities and services. At the standardization level, some of the key policies/procedures that have been identified and are being implemented for supporting ELM, are:

- Development of European standards for the realization, dissemination, implementation and exploitation of European key strategies such as European mobility and LLL (EU2020 and other communications by the EU).

- Development of European data models for the description of skills and competences

- Integration with systems e.g. knowledge management systems: Sharing of education related data, services, content and tools achieved through clearer technical agreements between all parties, without losing the value of expression typical of each European community's language and culture.

- Learning and employment opportunity exploration, management of individual learning pathways

- Development of quality frameworks, specifications and guidelines to improve the quality and transparency of organisations, processes, products and services

\section{iii. People (Stakeholders)}

a. Policy and governmental stakeholders

Policy and governmental stakeholders include (apart from the European Commission responsible for the policy context presented above) national and state government industries. The interests of these bodies are similar in nature to those of the EC. Many governments have a policy of supporting lifelong learning, in recognition of the fact that few jobs last for a whole working life, and citizens need to continue their learning, education or training recurrently. In other words, citizens need to be mobile, between different employments, and between employment and LET. European governments are committed to implementing Europass and they wish to be able to do that without unnecessary expense. More broadly, they are committed to implementing the Bologna process for higher education, alongside the other related processes. One expression of this commitment is the appointment of "Bologna Promoters" — professional's active in higher education who advise and work with peers on the implementation of the Bologna reforms.

Governments also tend to share with the EC a strong interest in quality assurance in higher education, to preserve the prestige of European higher education and the institutions involved. The European Association for Quality Assurance in Higher Education (ENQA) is a body that supports quality assurance, partly through their "Standards and Guidelines for Quality Assurance in the European Higher Education Area" (ENQA 2013). 


\section{b. Users of learner mobility services}

Leaners have a broad range of direct interests in learner mobility and related procedures and documents:

- They may wish to study away from their home country as well as at home, in which case procedures need to be in place both for their study in different places to be harmonized, and for the results of study in one country to be accepted in the context of another country.

- They may be involved in a study program that includes courses to be taken with another LET provider, possibly in a different country.

- They may wish to work in a different country from the one in which their studies were completed. In this case, the results of their studies need to be understood and accepted by potential employers in other countries.

- Even if they do not move between countries, they may still have an interest in assembling and using information about their learning and its results. This information can be used either to support filling in application forms by hand, or more directly, if in a suitable common electronic format, it could easily be transferred between the place it is stored and the place it is asked for.

c. Learning, education and training institutions

These bodies have quite a few distinct but related interests in learner mobility processes. The information may be used by central administration, by faculties and departments, or by international relationship offices (IROs):

- They need to comply with regulations concerning the ECTS and (for European Higher Education Institutions (HEIs)) the Europass Diploma Supplement (DS). They would like to do this efficiently.

- In any case, they need a coherent approach to reporting educational achievement. It makes a great deal of sense for this to be harmonized across different cases, so that the processes needed for reporting (e.g. the Europass DS) are largely common with the processes for any national requirements.

- Many institutions strive to keep students from dropping out of courses before completion. Any initiative that can maximize student retention is highly prized. One approach to this is a better level of assurance of suitability of applicants for programmes, and this in turn can potentially be provided by more accurate recognition of student abilities and achievements.

- In the process of admitting students, results from previous studies form an important basis. This information is mainly used to control required qualifications for the study applied for. Further on, this information can also be used as a basis for ranking people.

- If a learner, admitted to a course of study, has previously completed a learning opportunity at a comparable level, this may be recognized as partly overlapping the new study. In the process of recognizing the earlier education, it is important to gain detailed information about it, both at programme level and at the level of modules, so that any credit obtained in previous education can be credited to the current course.

- LET providers may define part of a study programme to be taken away from the home institution, in a different institution in the same country or abroad. 
The HEIs have started to apply these transparency processes and make use of relevant transparency tools have been confronted with the administration cost of manual and labour-intensive information management. Consequently, the need for related support services at a European level, ranging from secure management and exchange of learning-related history, goals and accomplishments, to new learning and employment opportunities discovery, constitute clear "business cases" in the evolving European educational setting.

\section{d. Employers}

Employers also potentially have much to gain from learner mobility:

- If information about the achievements is held in central repositories, it may enable them to search for suitable graduates.

- If the information about learning outcomes is recorded clearly, employers can have a better awareness of knowledge, skills and competences of potential employees, and so can fit them better into their required roles.

- If their employees engage with professional development, through the company or through professional bodies, achievements and competences recorded during education may feed through into the professional development record, making it easier and quicker for new employees to start their development processes.

\section{e. Recruitment service providers}

As agents of employers, these organisations share many interests with employers. However, because they routinely deal with many "candidates", they are likely to benefit even more from the automation of routine processes, and the use of machineprocessable information. A clear example of this kind of efficiency gain is where a recruitment agency imports academic records direct from the providers (e.g. Diploma Supplements from universities), and uses that information to fill in the education section of online CVs. Examples similar to this can be seen with the Europass Curriculum Vitae and Almalaurea, Monster and other web-based recruitment portals.

A future ambition of these organisations may well be to bridge the gap between academia and the workplace by having a "common currency" for educational competences or other achievements or learning outcomes that relate to job requirements.

\section{f. Developers and implementers}

Industry is demonstrating a vivid and growing interest in the production of learner mobility related standards. In the Gartner Industry Research document issued on 200712-12 titled "Findings: Bologna Process Demands True International Student and Course Data Standards in Higher Education Throughout the EU" (by Jan-Martin Lowendhal), it is highlighted that "the Bologna process has reached the stage where international student and course data standards have become necessary for the efficiency needed to support student mobility", and that "the Bologna Process, aimed at establishing a common and transparent framework for European structures of higher education, is finally starting to make a broad impact on the design requirements of IT solution".

Benefits that may be of interest to these businesses include: 
- simpler handling of personal educational achievement information across systems;

- compliance with Bologna Process and market requirements;

- enhancing products with automatic functionalities for "producing" and "consuming" learner mobility documents and reports;

- interoperability among student information systems by sending electronically structured data from institution to institution eliminating the paper processes;

- exposing achievement information for consumption of the Recruitment service providers or companies;

- feeding academic records of students to national or European databases.

\section{iv. Processes (business cases) and origin of mobility-related information}

According to the aforementioned stakeholder-centric analysis main benefits and interests for all parties can be summarized in the following business cases

- Exploitation of academic achievements abroad to further continuing education or seeking jobs opportunities abroad

- Acknowledgement of previously achieved credits and academic generic achievements, domestically and internationally

- Facilitation of incoming and outgoing mobility within the same country, across multiple countries, and/or from one field of studies to another

- Integration of foreign workers into the local work world

- Communication of the level, content and nature of qualifications to potential employers, domestically and internationally

- Contribution to the harmonization of higher education achievements and qualifications, domestically and internationally

Information relevant to learner mobility documents arises from different educational processes within and beyond the institutions, and may currently be stored in various places. These include:

- sources of information at a national level;

- course advertising materials;

- ECTS course catalogues;

- student record systems;

- agreements/contracts for exchange of students between institutions and for joint collaborations;

- learning agreements;

- exchange programme nominations;

- employers' records of their employees / human resource systems;

- personal and professional development processes, and related records;

- systems managed by the learner, such as e-portfolios, and their related processes.

Concrete examples of such processes and associated information are:

a. Description of learning opportunities

Both whole programmes of study and their component modules are established and revised frequently, often on a yearly basis. There are institutional routines for these processes, and they include different levels of approval of the programme. In the process of revising the course or programme catalogue or prospectus, the description 
of the programmes will be updated. For some programmes, there is a national overall plan for the study that includes some of the description. It is important to have versions of descriptions that makes it possible to recapture the description for each student at a later time.

\section{b. Generic information for the Diploma Supplement}

Parts of the Diploma Supplement and other mobility documents are standard within a country, but differ between countries. This is common particularly for section 8 of the DS, but may also occur with other sections. This information will need to come from a national body.

\section{c. Personal information}

Information about a learner (name, address, etc.) is first given to an educational institution in the processes of application and admission. Later on, this information is maintained by the student or administration in different registration processes. This is often done each semester. It is common to retrieve personal information from other national sources. In some countries, the learner's name and official home address are maintained on an official national register, and can be retrieved from this register.

\section{d. Learner qualifications}

The assessment itself can be initiated by the institution, or by the student, in cases where the institution does not notice that the student has fulfilled the conditions of a qualification. This process includes checking the requirements for the programme, and all the information about assessment results has to be collected and recorded. This ends up with producing documents for the qualification (Diploma, Transcript, Diploma Supplement etc.). These processes can be anywhere from fully manual to fully automatic.

e. Module results

Information about module results arises primarily from two different processes:

- The most common is results based on an examination process, or from the evaluation of some sort of coursework or dissertation. This process includes registration for classes and examination, the examination, the evaluation and registration of the results. After this, complaints from the students may be treated, before the results are final.

- Also results gained at other institutions can be included in the qualification. These will be included as a result from a process of recognition. This process is based on information from other institutions.

Figure 3 presents a high-level developing model of the educational practice relevant to the learner mobility domain in the context of which information arises - that is, the practice that generates information, parts of which are gathered together in mobility documents and reports. This illustrates the rough division of the subject matter into three distinct parts:

- learning opportunity provision

- assessment

- award of credit or qualification 
Between these parts sits the learner, his or her actions, and evidence of those actions, which provide the basis for the rest of the system. (Evidence can include test results, or records of consequences or effects, or can be just in the memory of observers.) The process of learner action is shown as an oval. Both the learner, and the material evidence are depicted as things in the world that are caused or produced by learner action.

Intended learning outcomes act as the proper bridge between learning opportunity provision and assessment. Without this bridge, the connections are much less clear.

\section{[FIGURE 3 ABOUT HERE]}

\section{v. Software services}

On the basis of the provided stakeholder, procedure and information analysis, it is evident that a plethora of software services are related to the support of learner mobility related processes. These services, as depicted in Figure 1 include:

- e-application and e-admission HEI systems

- Course catalogue and course marketing systems

- Achievement and credit transfer services

- E-portfolio systems

- Individual Study and Personal Development Planning

- Learning Opportunity Exploration

- Employment exploration and job application

\section{vi. Information models and data structures}

Having gathered and analysed the domain's existing practice and taking into consideration the main requirements for technological products to support learner mobility processes within and across European institutions, an information model on achievement information has been produced and currently constitutes a European Norm on European Learner Mobility Achievement Information (EuroLMAI)

The EuroLMAI domain model is concerned with specific sets of learner achievement information arising from the different administrative processes carried out at the institutions throughout the implementation of educational practice, as well as with the associations amongst them. It builds upon information regarding the learner, the description of learning opportunities, assessment of qualification for a specific learner and result information for each completed learning opportunity.

In essence, the EuroLMAI model defines the assemblage pattern of such information in terms of an achievement report configuration, consisting of:

- a Learner instance, representing the individual enrolled in a formal learning opportunity (part or full programme of study, course, work experience, etc.) 
- an Issuer instance, representing the authority that awards credits and/or qualifications and/or attests learner participation in the described learning opportunities including any associated results gained

- at least one Learning Opportunity object, which, depending on its function and level, may comprise any or all of the following information:

(a) description of a learning opportunity or period of learning the learner currently or formerly enrolled in, and in case of successful completion, of the qualification achieved, including the actual result for the specific learner

(b) description of possible component units (each of which may contain provider, credit, and result information for the specific learner), and optionally,

- a set of Additional Information properties

To maintain the systems perspective during the specification and analysis of the system (Dhukaram and Baber 2016), attention is drawn to the creation of UML class diagram (Figure 4) (CEN Technical Committee 353 (2010)) for an explanation of the underlying semantics of this diagram. Each box in the diagram relates to a Class. Each named association (line with label) in the diagram represents an Association Property. The Resources of this model are either defined in this specification or in other standards referred to in the following subclasses. Attribute Properties from other relevant standards have also been reused. Arrows on named associations indicate the direction in which traversal between instances can occur. No cardinality is specified for any association. Lines with an unfilled diamond shape represent an association with an aggregation relationship, indicating that one class is a part of another class.

\section{[FIGURE 4 ABOUT HERE]}

Bindings of the information model have been defined and constitute the basis for Information Systems data exchange. UK and Nordic related systems are currently based on the EuroLMAI Standard.

\subsubsection{Summary}

The ELM case study regards a set of technical standards addressed to European system developers (HE providers or vendors that want to develop interoperable services, e.g. recruitment systems, etc.) using STS design approach. STS perspective has led to the development of LET specifications and standards for formal standards, consortium specifications and community specifications (Hoel and Pawlowski 2011).

Norway has already implemented the national student management system infrastructure on the basis of EuroLMAI (USIT 2013). In addition, the electronic UK HEAR (JISC 2012) has been developed on the same basis. There is currently an effort for expanding usage in other member states. Norway has informed us that all Nordic countries (Sweeden, Finland) are in the process of integrating the standard into their services. Currently similar efforts are carried out in Greece for implementing ELM. The vision is to have European-wide interoperable services electronically exchanging information for HE provision. 


\subsection{Case Study 2: Enterprise System Management (ESM) Course}

The Higher Education sector has seen several transformation over the years including a decrease in government funding for UK universities. As result, universities explore new sources of revenue, for example increasing the number of full cost courses that provide vendor qualification and real industry experience and projects for the students. There are several consequences arising from these changes; including a varied group of students in postgraduate education. Reflecting on Enterprise Systems Management (ESM) course, which is offered by the school of engineering, design and manufacturing systems at Birmingham City University. This course aims to equip students with knowledge to solve complex systems problems and manage systems using engineering and systems principles. This course draws on design thinking and systems engineering, to provide students with the skills to re-engineer processes, integrate and manage complex systems. Generally, the class comprises of 30 students ranging from 21- 45 years. Out of the 30 at least 20 are international students and possibly only $40 \%$ have relevant work experience. This example highlights that the student groups have varied background, experience, and ethnicity as well as age difference, which demands a fresh and effective approach to the delivery of the courses to enhance the overall learning experience and employability.

Loo (2004) recommends using a variety of learning methods as this will facilitate defining a unique learning and teaching approach. Despite the diversified student groups enrolled in the courses, traditional approaches used over the years do not encourage effective learning and create a division between the knowledge provider (lecturer) and receiver (students). In some instances the different ethnicity and background may lead to language barriers that introduce a huge possibility of the students not grasping the knowledge shared in traditional approaches. This behaviour deviates from some of the characteristics, pointed out by Haddock (1993) such as the ability to understand, encourage and support the students' uniqueness and being sensitivity to their needs. In order to overcome this situation modern learning and teaching approaches, adopt practical teaching styles and course design using a student centric approach; though the success of this approach is loosely dependent on the individual lecturers, as they may have competing and opposing demands (Huddleston and Unwin, 1997).

\subsubsection{STS perspective}

STS design approach is discussed using Cognitive Work Analysis (CWA) (Vicente 1999) as an example to provide a systems-level view which allows the analysis to consider how different elements of the system might contribute to the functional purpose (rather than assuming, for instance, that there is only a single element like technology or human). CWA is a structured framework for analysing complex STS such as command and control (Chin et al., 1999; Naikar et al.,. 2001), process control (Vicente 1999) and medical decision making (Dhukaram 2011). As this paper is focused on introducing STS thinking approach, Work Domain Analysis (WDA) the 
initial phase of CWA is used to model education ecosystem. In education and training WDA is used as an integrative framework to structure the course content (Dainoff et al 2002) and design for Australian Defence Force (Lintern and Naikar 1998).

WDA analysis is conducted using abstraction hierarchy (AH), a modelling tool used to identify the functional structure of the domain. Using $\mathrm{AH}$, the work domain is analysed through five abstractions, linked by the means-ends relationship to identify the functional structure of the domain. AH involves five levels of abstraction as shown in Table 2 to conduct a vertical analysis across the hierarchical levels. Using the example questions in Table 2, Figure 6 provides an example of how AH has been used to model the course provision for Enterprise Systems. Although Figure 6 does not provide a full analysis it highlights:

- how the education provision can be modelled;

- how CWA helps to provide a high level view of the socio-technical system; and

- how the various layers in education provision are mapped onto the levels of complex socio-technical system.

[TABLE 2 ABOUT HERE]

Drawing from the different $\mathrm{AH}$ levels (Figure 5) the course dynamics and integration is explained next starting from the lower level physical form towards functional purpose to highlight the alignment of course design with social-technical thinking.

[FIGURE 5 ABOUT HERE]

\section{i. Physical Form (Stakeholders and Technology)}

This includes the soft and hard elements required for the delivery of the course. The Enterprise Systems Design module utilises several physical form to deliver the course, for example the industrial experts, researchers, the lecturers, teaching assistants and students, that forms the core of the human aspect. While in technology, having license for the Enterprise Resource planning (ERP) systems offers students' access to a software offers end-to-end process that required to be re-engineered to fit into the organisation mode of operating. This provides the students to gain a better understating of how to re-engineer processes and to achieve end-to-end system integration based on industrial case studies. . 


\section{ii. Object-related Functions (Delivery)}

The course delivery uses numerous activities, such as short lecture series, case studies, discussion, and practical sessions. This mode of delivery, allows students to work in groups, facilitating students learning from each other, and offers an environment that enables collaboration and effective sharing of knowledge. As a result, it encourages students to reflect on the key concepts and ideas put forward throughout the sessions, and potentially enhance the learning experience and performance. In addition, it offers remote access to the ERP systems, encouraging students to practise and hone their skills, whenever it is convenient for them. Offering group assignment introduces a setting in which students have to interact with each other, collaborate, and exchange ideas about the subject. In return, students control their learning as they address realworld challenges and the lecturer becomes a provider of a nurturing environment that guide students' to achieve the threshold of their own mind. Whenever people are working in teams, team dynamics such as personality differences or other dysfunctional behaviour are unavoidable (Colbeck et al., 2000); though such challenges facilitates gaining several appropriate qualities and skills, such as teamwork, communication, resolving disputes, responsibility, common understanding, and respect for others (Joham and Clarke, 2012).

In addition, the delivery of the session was supplemented with different activities in order to accommodate student different levels of motivation, and responses to a specific classroom setup and teaching approach (Felder and Brent, 2005).

\section{iii. $\quad$ Purpose-related Functions (Business Processes)}

Some of the purpose-related functions identified to achieve course goals are: communications, collaboration and problem-solving capabilities to facilitate in knowledge gaining, teamwork and resolving disputes not just within the students. Communication and collaboration are also important as course is delivered in conjunction with industrial experts and researchers relevant to the domain, in order to expose the students to industrial challenges, industrial expectations of graduates and latest trends and challenges in the domain. Combining the three worlds together, that is academia, research, and industry is meant to allow the students to build confidence in their training and understand the relevance of what they are learning.

\section{iv. Values and Priorities (Organisational Policies, procedures and laws)}

While adhering to the university culture, policies, vision and the government laws for HE course provision, various procedures, protocols and risk management procedures are created to ensure that the ESM HE goals are met along with student's success factors, such as student marketability and employability. 


\section{v. Functional Purpose (ESM Goals)}

The goal in this case study is the provision of ESM course for postgraduate students with varied experience, age and background.

\subsubsection{Results and Summary}

In order to address the effectiveness of STS approach in preparing and delivering the module, a survey questionnaire was implemented as an approach for collecting data. There were several reasons for using a survey questionnaire, one it allows to collect similar data from a group of students (Oates, 2006). Second it enables to gather factual information which provides an inclusive coverage of relevant facts (Denscombe, 2010), thus allowing to correlate information from the different students. Thus, administering a survey questionnaire allowed narrowing down the focus of emerging trends and identifying the areas requiring further exploration, along with collecting precise and valid responses.

The students were handed the questionnaire after the fourth session, as this allowed to gather initial findings and make adjustments for future deliveries to accommodate any shortcomings suggested. The instrument included closed-ended questions, which asked the participants to indicate their level of agreement or disagreement based on a five point Likert scale (Cohen et al., 2000). The study makes use of purposeful sampling by selecting only the students that were involved in this specific module, as they were the only ones to have first-hand experience.

The study targeted 20 students, however only 17 student opted to participate in the study, and all of them completed the questions in the survey. Table 3 illustrates the results from the different questions that were posed to probe information from the students about the design and delivery of the course module.

\section{i. Results}

The initial findings are promising, with 59\% of the students suggesting that the sessions were well organised and it stressed the important concepts which provided them with an in-depth understanding of the topic being studied. However, 29\% of the students found the workload to be heavy and $35 \%$ found the session difficult. Overall $71 \%$ of the students felt that the sessions were enjoyable and was relevant to their degree. This indicates that students were encouraged with the level of interaction among themselves and the lecturer, which facilitated them to share their experiences. In addition, these results indicate a promising outcome when using an STS approach, suggesting that placing social aspects at the centre of the course design and planning could provide an effective teaching approach.

[TABLE 3 ABOUT HERE] 


\section{ii. Summary}

Drawing from these preliminary results, one possible explanation for the students finding the sessions complex, difficult and not easy to follow could be associated with most students not having formal industrial experience and failed to cope with other students with such experience. Since the delivery approach depended on students interacting and sharing their experiences to support their own learning; thus, the students with industrial experience dominated, which caused the other students to disengage from the sessions. Another reason could be associated with social and cultural issues inhibiting students, as most of the students were young international students, who were not used to such a delivery approach. Thus, failed to collaborate and see the need to exchange ideas, because for them it was the lecturer's duty to share knowledge and experience.

On the other hand, the manner the sessions were organised and delivered allowed the students to gain a better understanding of the subject domain. A possible explanation for such diversified outcome where many students found it difficult to collaborate and engaged, yet believed the approach was appropriate can be due to the students understanding the significance of collaborating and interacting among themselves; and saw it as an opportunity to gain and enhance their knowledge and gain broader understanding through drawing from the other student experience and the industrial experts.

This finding shows that the application of socio-technical systems thinking helps to enhance reasoning and critical thinking, along with an in-depth understanding of subject domain. In addition, it stimulated students to learn not only theoretical aspects of the course but also provided the environment to gain key valuable skills such as communications, collaboration and problem solving; which ensures students are knowledgeable and marketable. Thus, it can be argued that adopting this STS approach encouraged conceptualisation, abstraction and formation of new knowledge, which potentially lead to better understanding of the concepts. However, further studies that can provide statistically significant results need to be undertaken, to offer any conclusive usefulness and effectiveness of this approach within an HE environment.

\section{Conclusion}

The purpose of this paper is to present the complexity of HE provision and how STS approach can be used to capture and model the interactions and relationships between the people, technology and the organisations. By adopting STS perspective various stakeholders were identified along with their roles and responsibilities in the system, the business processes that need to be considered, organisational policies and procedures that affect the processes and the technological needs. 
EuroLM case study shows the STS design approach for the domain modelling including policy context, people, processes, technology and data structures to create a roadmap for planning ICT standards for leaner mobility targeting specific stakeholders and environments as shown in Figure 5.

The ESM case study shows the course provision for master degree student groups that have varied background, experience and ethnicity as well as age difference. STS perspective is used to enhance the overall learning experience, developing the next generation of the students as innovative thinkers as reflected in the preliminary survey and to achieve the organisational goals.

The case studies present simple yet powerful representations of the deep intertwinement, interactions, relations and interdependencies in the HE ecosystems between the stakeholders, organisation, processes and technical aspects. By examining the complex relationships and interactions around the work organisation HE providers can understand the wider social context in which the work is done and better understand the community needs and challenges similar to engineering education provision (Conlon 2008; Lucena and Schneider 2008). This shows the value of applying a structured and a systematic way for analysing and reducing the complexity in the systems. Moreover, STS perspective transforms our view of the ecosystem offering a different dimension to the thinking.

This paper does not suggest that STS design will lead to the development of better systems norSTS is the only design approach that can be used for complex systems. The paper helps to guide engineering education and HE providers to understand the education ecosystem, role of the stakeholders and how education ecosystem can be conceptualised and modelled through STS perspective that includes technical systems, business processes and the various stakeholders who use and interact with the systems governed by organisational policies.

\section{Acknowledgment}

ELM work was supported by the European Committee for Standardization under Grant BC/CEN/ENTR/000/2008-30

\section{References}

Barak, M., \& Williams, P. (2007). Learning elemental structures and dynamic processes in technological systems: a cognitive framework. International Journal of Technology and Design Education, 17(3), 323-340.

Belmonte F et al., (2011). Interdisciplinary safety analysis of complex sociotechnological systems based on the functional resonance accident model: An application to railway traffic supervision. Reliability Engineering and System Safety 96 (2011) 237-249

CEN Technical Committee 353 (2010). European Norm (EN) 15981 - European Learner Mobility Achievement Information Model (EuroLMAI). 
Chin M, Sanderson P, Watson M, (1999). Cognitive work analysis of the command and control work domain. Proceedings of the 1999 Command and Control Research and Technology Symposium.

Cohen, L., Manion, L. and Morrison, K. (2000) Research methods in education. 5th ed. London ; New York: RoutledgeFalmer, p.446.

Colbeck, C.L., Campbell, S.E. and Bjorklund, S.A. (2000) Grouping in the Dark: What College Students Learn from Group Projects. The Journal of Higher Education, 71(1), pp. 60-83.

Conlon, E. (2008). The new engineer: between employability and social responsibility. European Journal of Engineering Education, 33(2), 151-159.

Cooper, A. (2010) Key Challenges in the Design of Learning Technology Standards: Observations and Proposals. International Journal of IT Standards and Standardization Research, 8(2), pp. 20-28.

Cooper, R., \& Foster, M. (1971) Sociotechical systems. American Psychologist, 26, 467-474.

Dainoff, M. J., Mark, L. S., Hall, C., \& Richardson, A. R. (2002, September). Cognitive work analysis in education and training: relating pedagogical methods to course objectives. In Proceedings of the Human Factors and Ergonomics Society Annual Meeting (Vol. 46, No. 8, pp. 825-828). SAGE Publications.

Davis, M. C., Challenger, R., Jayewardene, D. N., \& Clegg, C. W. (2014). Advancing socio-technical systems thinking: A call for bravery. Applied ergonomics, 45(2), 171180.

Denison, D.R., Hooijberg, R. \& Quinn, R.E.: Paradox \& Performance: Toward a Theory of Behavioral Complexity in Managerial Leadership, Organization Science, 6,5:524-40 (1995)

Denscombe, M. (2010) The good research guide for small-scale social research projects. Maidenhead, England: McGraw-Hill/Open University Press.

Dhukaram V A and Baber C (2011). An approach to designing interactive decision support system for cardiac patients. HCI 2011 conference, Newcastle Upon Tyne UK, July 2011.

ENQA (2013) Standards and Guidelines for Quality Assurance in the European Higher Education Area. Available online at: http://www.enqa.eu/wp-content/uploads/ 2013/06/ESG_3edition-2.pdf 
European Commission (2008) New Skills for New Jobs - Anticipating and matching labour market and skills needs. Available online at http://eur-lex.europa.eu/ LexUriServ/LexUriServ.do? uri=SEC:2008:3058:FIN:EN:PDF

European Committee for Standardization (CEN) Workshop on Learning Technologies (2010) Guidelines on a European Learner Mobility Model - CEN Workshop Agreement document 16133:2010.

European Committee for Standardization (CEN) (2014) European Standardization. Available online at: http://www.cencenelec.eu/standards/Pages/default.aspx

European Commission (2009) Strategic framework for European cooperation in education and training. Available online at http://eur-lex.europa.eu/LexUriServ/ LexUriServ.do?uri=OJ:C:2009:119:0002:0010:EN:PDF

European Parliament and The Council (2004) Decision No 2241/2004/EC on a single Community framework for the transparency of qualifications and competences (Europass). Available online at http://eur-lex.europa.eu/LexUriServ/LexUriServ.do? uri= OJ:L:2004:390:0006:0020:EN:PDF

Felder, R.M. and Brent, R. (2005) Understanding student differences. Journal of Engineering Education, 94(1), pp.57-72.

Gattie, D. K., Kellam, N. N., Schramski, J. R., \& Walther, J. (2011). Engineering education as a complex system. European Journal of Engineering Education, 36(6), 521-535.

Haddock, J. (1993) Profile of a Nurturing College Professor. Journal of Engineering Education, 82(1), pp.34-37.

Handy, 1993 C. Handy Understanding Organizations (fourth ed.)Penguin, London, UK (1993)

Hoel T. and Pawlowski J. (2011) Modelling the CEN WS-LT Standardisation space. IEEE Computer Society Learning Technology Newsletter, 13(3).

Huddleston, P. and Unwin, L. (1997) Teaching and learning in further education. First Edition ed. London; New York: Routledge.

International Organization for Standardization (ISO) (2014) What is a standard? Available online at: http://www.iso.org/iso/home/standards.htm

Joham, C. and Clarke, M. (2012) Teaching critical management skills: the role of problem-based learning. Teaching in Higher Education, 17(1), pp.75-88.

Joint Information Systems Committee (JISC) (2012) Higher Education Achievement Report (HEAR) XML Data Specification: Relationship with Standards. Available online at: http://www.xcri.co.uk/HEAR/HearTechStandardsBrief_v1.0.docx 
Joint Information Systems Committee (JISC) (2013) Course-related processes. JISC Infonet. Available online at: http://www.jiscinfonet.ac.uk/infokits/courseinformation/what-is-course-information /course-related-processes/

Kroes, P., Franssen, M., van de Poel, Ibo. \& Ottens, M. (2006): Treating socio-technical systems as engineering systems: some conceptual problems. Systems Research and Behavioral Science, 23(6):803- 814

Larson R. (2014) Service Innovation: Are We Creating Patchwork Quilts? The Case of Education. Comment on the Whitehouse Office of Science and Technology Policy's (OSTP) January 13, 2014 Federal Register Notice "High Impact Learning Technologies", pp. 153

Leavitt, H.J. (1965) "Applied Organizational Change in Industry: Structural, Technological and Humanistic Approaches," in Handbook of Organizations, pp. 114470, ed. James G. March. Chicago: Rand McNally.

Lintern, G., \& Naikar, N. (1998, November). Cognitive work analysis for training system design. In Computer Human Interaction Conference, 1998. Proceedings. 1998 Australasian (pp. 252-259). IEEE.

Long, S. (Ed.). (2013). Socioanalytic Methods: Discovering the Hidden in Organisations and Social Systems. Karnac Books

Loo, R. (2004) Kolb's learning styles and learning preferences: is there a linkage? Educational Psychology, 24(1), pp.99-108.

Lucena, J., \& Schneider, J. (2008). Engineers, development, and engineering education: From national to sustainable community development. European Journal of Engineering Education, 33(3), 247-257.

Naikar N and Sanderson PM (2001). Evaluating design proposals for complex systems with work domain analysis. Human Factors, 43, 529-542.

Oates, B. (2006) Researching information systems and computing. London: SAGE.

Qureshi, Z. H. (2007, December) A review of accident modelling approaches for complex socio-technical systems. In the proceedings of the twelfth Australian workshop on safety critical systems and software and safety-related programmable systems, 86, pp. 47-59. Australian Computer Society, Inc.

Richardson, J.T.E. (2011) Approaches to studying, conceptions of learning and learning styles in higher education. Applying styles research to educational practice, 21(3), pp.288-293.

Rompelman, O., \& De Graaff, E. (2006). The engineering of engineering education: curriculum development from a designer's point of view 1. European journal of engineering education, 31(02), 215-226. 
Scott Morton, 1991 M. Scott Morton The Corporation of the 1990s: Information Technology and Organizational Transformation Oxford University Press, Oxford (1991)

Sommerville, I, Cliff, D, Calinescu, R, Keen, J, Kelly, T, Kwiatkowska, M, McDermid, J \& Paige, R 2012, ' Large-scale complex IT systems ' Communications of the ACM, vol 55, no. 7, pp. 71-77.

Trist, E. (1950). The relations of social and technical systems in coal-mining. British Psychological Society, Industrial Section.

University Center of Information Technology (USIT), University of Oslo (2013) The Common Student (FS) System. http://www.fellesstudentsystem.no/english/applications/ 


\section{Government}

Laws Sanctions Policies Economics

Organisational and Regulators
\begin{tabular}{|llll|}
\hline Markets Conditions & Financial Pressure & Ownership & Affiliations \\
\hline
\end{tabular}

\section{Management and Procedures}

Management Models Service Provision Resource Generation

Financing Reporting Data Flow Rules and Norms

\section{People and their Roles}

Lecturer Assistants Tutors Students Partners Parents Administrators

Delivery

Online Face-to-Face Flipped Classroom Gamification 3D Printing

Hardware

Workstations Peripheral Electronics Networks Hubs

\section{Software}

Operating Systems Applications Software

Figure 1: An Overview of Higher Education Ecosystem constituents 


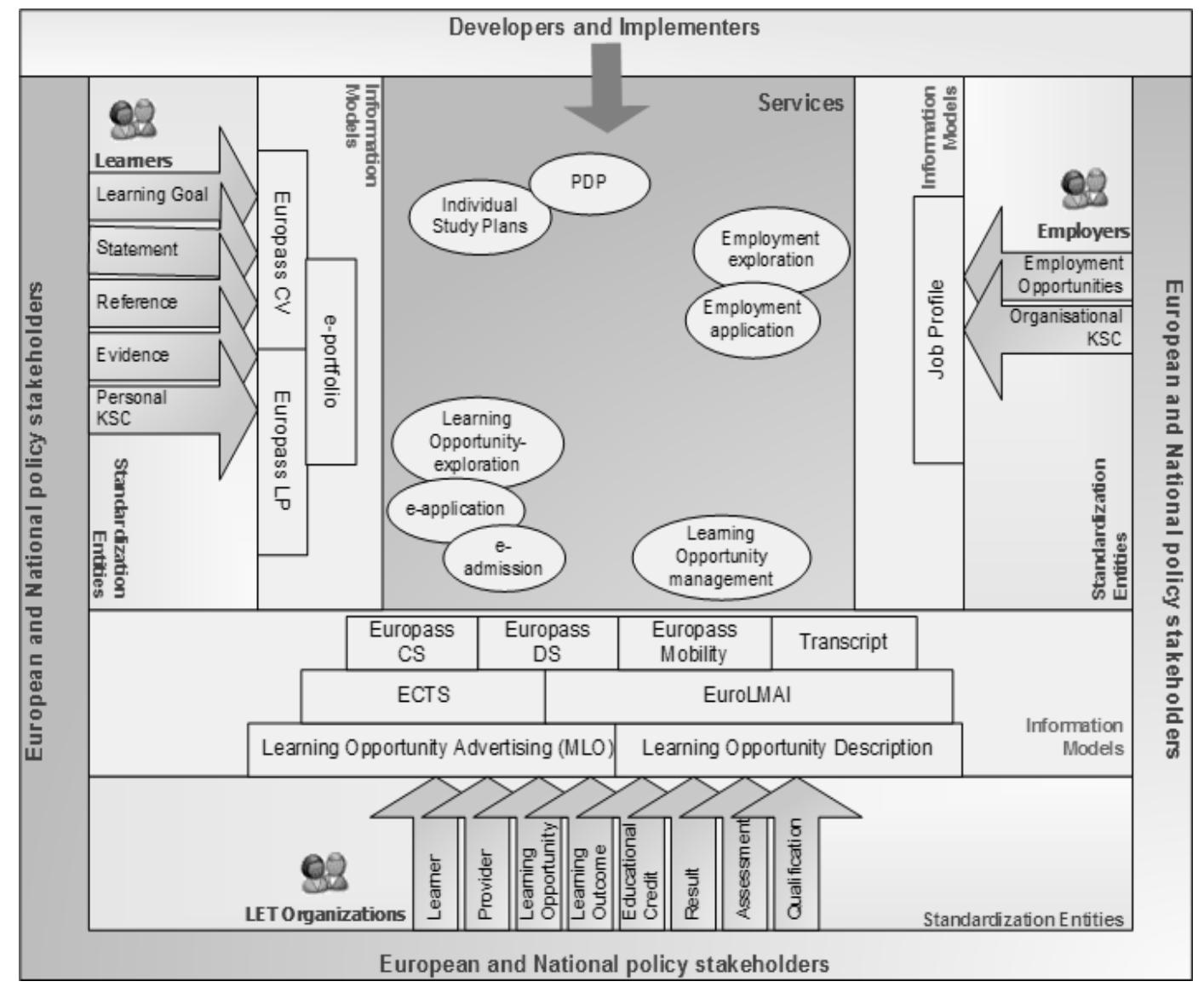

Figure 2: A diagrammatic representation of the learner mobility landscape 


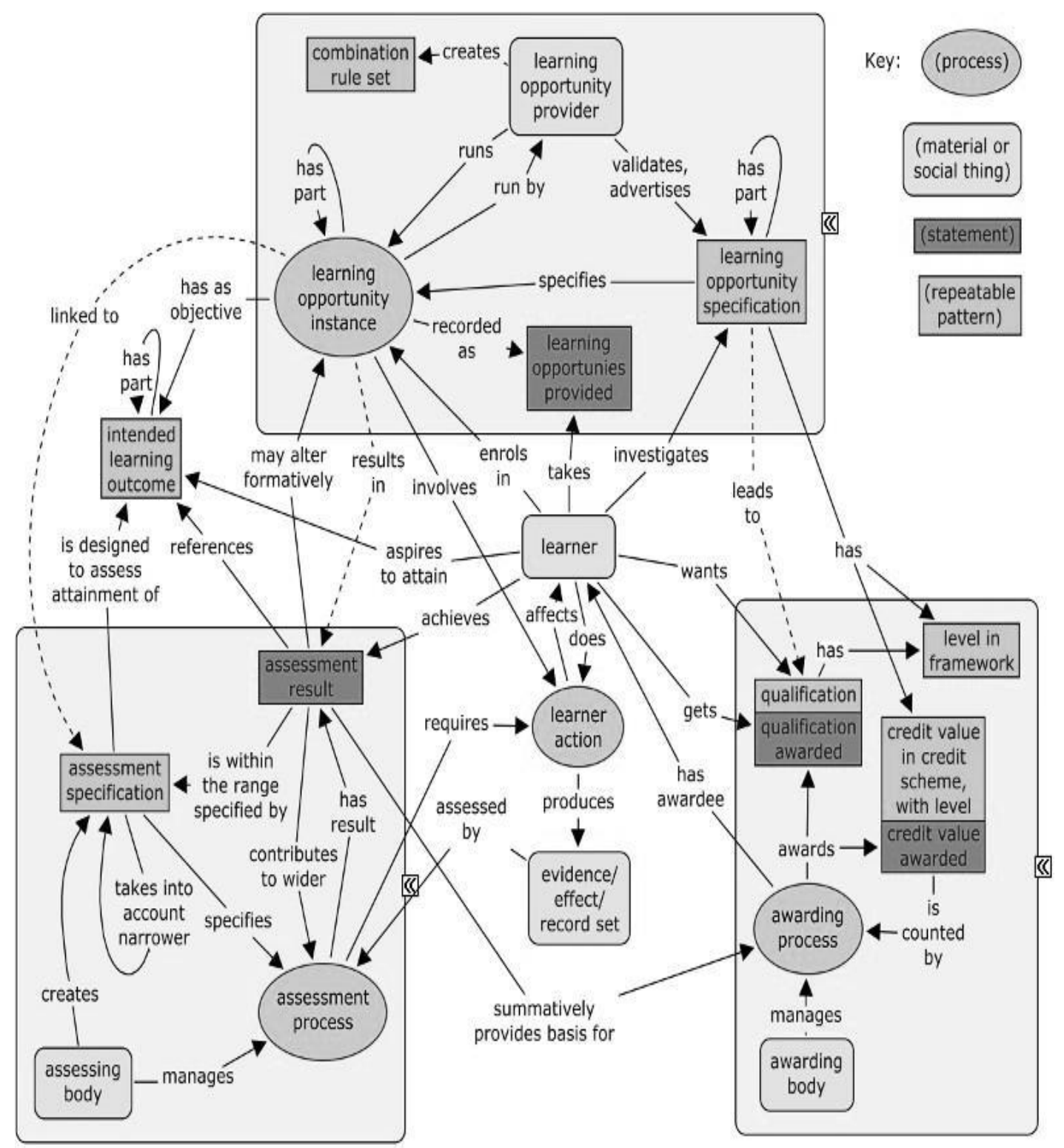

Figure 3: Conceptual model of educational practice and information relevant to learner mobility 


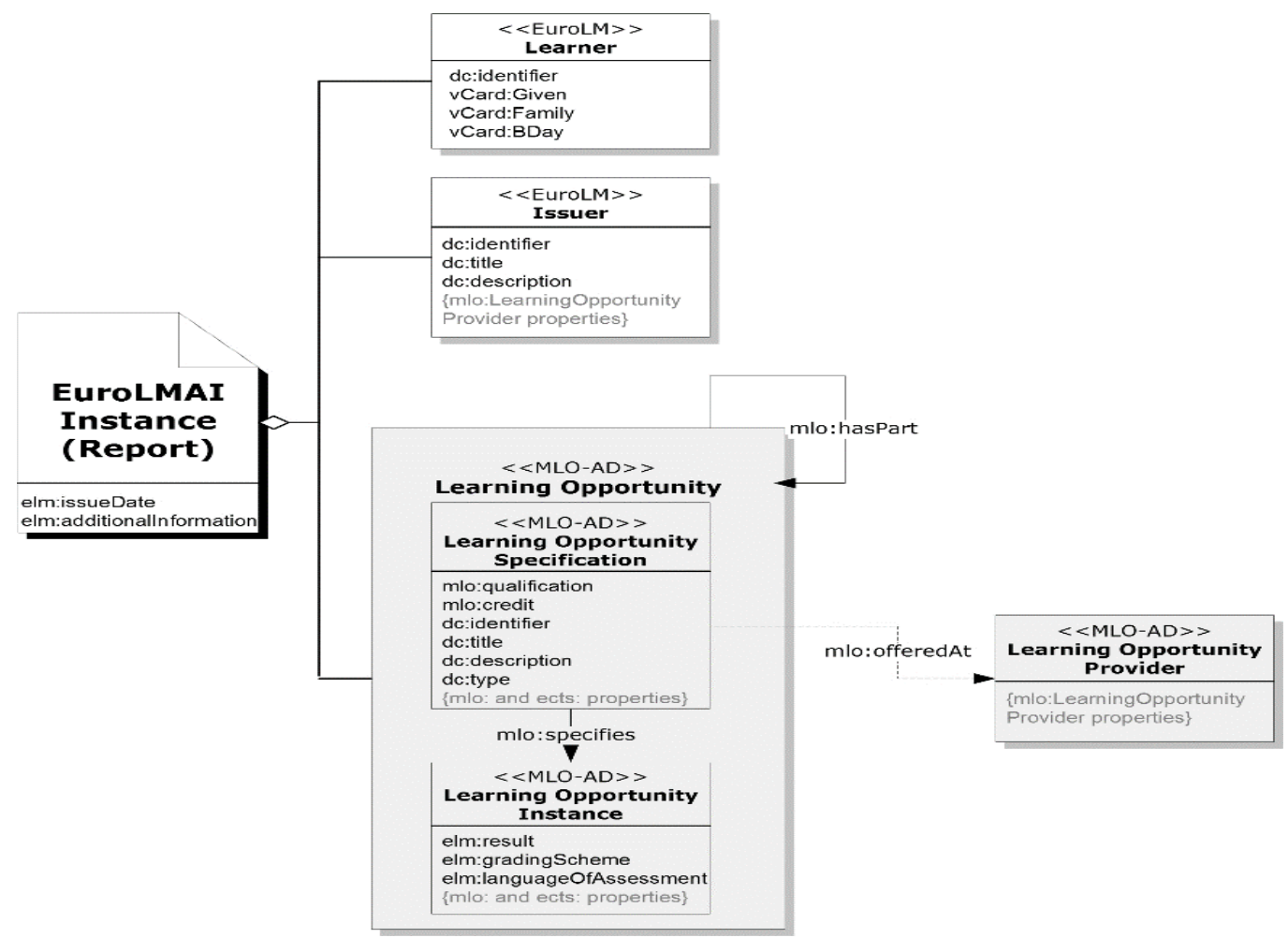

Figure 4: The EuroLMAI information model 


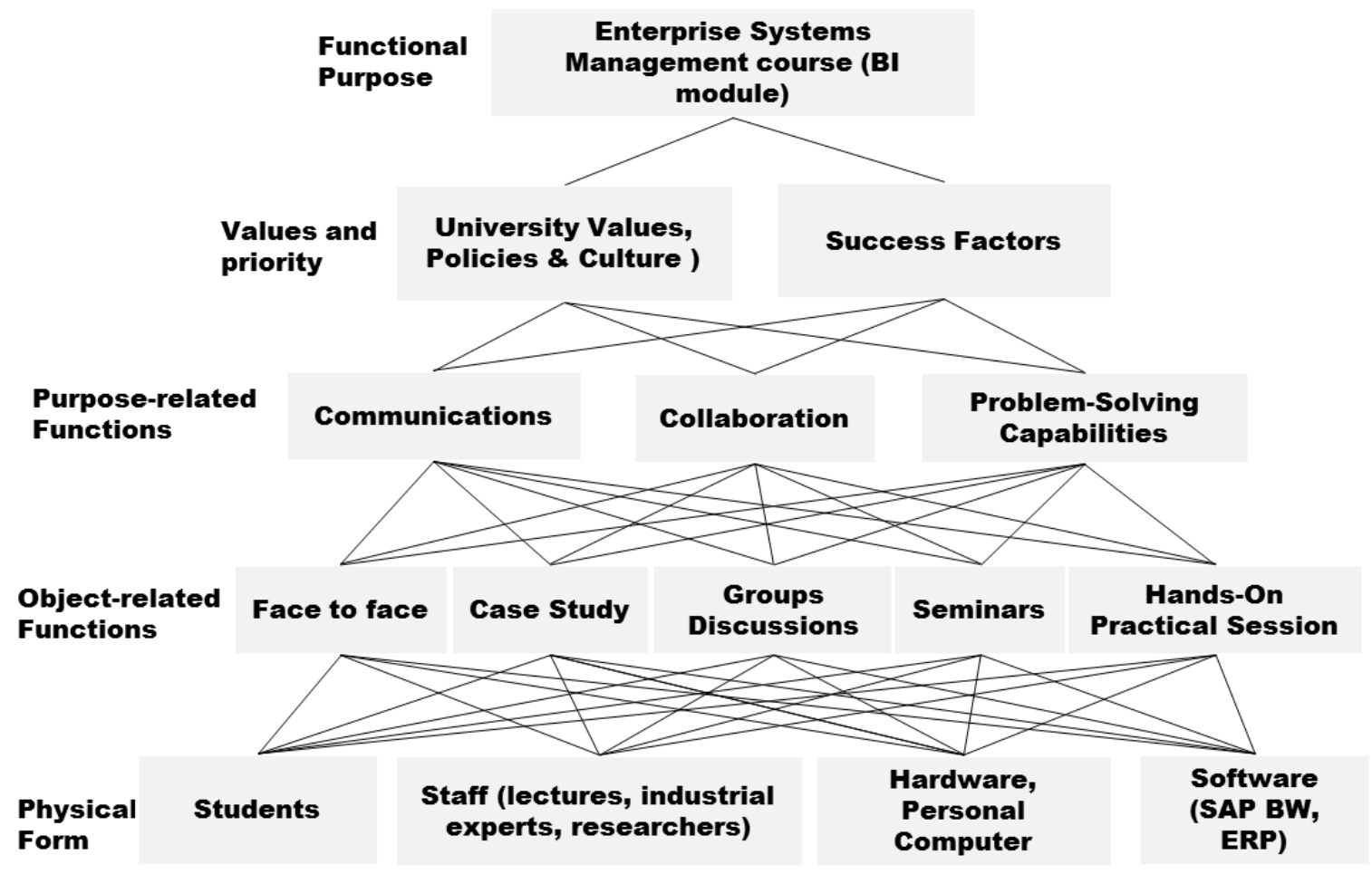

Figure 5: AH model for ESM Course Delivery 
Table 1: Data and Information Collection for STS (course/curriculum related processes)

\begin{tabular}{|c|c|}
\hline STS Design & Functions requiring data and information \\
\hline Planning & $\begin{array}{ll}\cdot & \text { strategic planning } \\
\text { - } & \text { portfolio analysis } \\
\text { - } & \text { market research } \\
\text { - } & \text { benchmarking } \\
\text { - } & \text { employer engagement } \\
\text { - } & \text { costing }\end{array}$ \\
\hline $\begin{array}{l}\text { Design and } \\
\text { Approval }\end{array}$ & $\begin{array}{ll}\text { - } & \text { learning design } \\
\text { - } & \text { validation } \\
\text { - } & \text { approval } \\
\text { - } & \text { quality assurance and enhancement design } \\
\text { - } & \text { professional accreditation }\end{array}$ \\
\hline $\begin{array}{l}\text { Delivery and } \\
\text { Review }\end{array}$ & $\begin{array}{ll}\text { - } & \text { admissions } \\
\text { - } & \text { enrolment } \\
\text { - } & \text { timetabling } \\
\text { - } & \text { attendance monitoring } \\
\text { - } & \text { summative assessment and feedback } \\
\text { - } & \text { records of achievement } \\
\text { - } & \text { graduation/awards } \\
\text { - } & \text { major/minor modifications } \\
\text { - } & \text { resource distribution } \\
\text { - } & \text { performance indicators/business intelligence/key information sets }\end{array}$ \\
\hline Communicating & $\begin{array}{ll}\text { - } & \text { marketing } \\
\text { - } & \text { employer engagement } \\
\text { - } & \text { student handbook/information } \\
\text { - } & \text { professional, statutory and regulatory body requirements } \\
\text { - } & \text { statutory reporting } \\
\text { public information }\end{array}$ \\
\hline Student support & $\begin{array}{ll}\text { - } & \text { access to resources/service } \\
\text { - } & \text { learning analytics } \\
\text { - } & \text { personal development planning } \\
\text { - } & \text { alumnility/credit transfer } \\
& \text { alations/destinations }\end{array}$ \\
\hline
\end{tabular}


Table 2: Work Domain Analysis

\begin{tabular}{|c|c|c|}
\hline $\begin{array}{l}\text { AH } \\
\text { Abstractio } \\
\text { n Level }\end{array}$ & Abstraction Label & Examples of Questions to Ask in the Analysis \\
\hline 1 & Functional Purpose & What is the goal or purpose? \\
\hline 2 & $\begin{array}{l}\text { Values } \quad \text { and } \\
\text { Priorities }\end{array}$ & $\begin{array}{l}\text { What high level functions take place to achieve the } \\
\text { functional purpose? }\end{array}$ \\
\hline 3 & $\begin{array}{l}\text { Purpose-related } \\
\text { Functions }\end{array}$ & $\begin{array}{l}\text { What functions take place to achieve the functional } \\
\text { purpose? What are the constraints? What are the } \\
\text { priorities? }\end{array}$ \\
\hline 4 & $\begin{array}{l}\text { Object-related } \\
\text { Function }\end{array}$ & What is needed to support the generalized functions? \\
\hline 5 & Physical Form & $\begin{array}{l}\text { What properties or attributes or physical objects (like } \\
\text { hardware) help in supporting the object-related } \\
\text { function? }\end{array}$ \\
\hline
\end{tabular}


Table 3: Preliminary survey results

\begin{tabular}{|c|c|c|}
\hline Question & Likert Scale & $\begin{array}{l}\text { No. of Responses } \\
\text { out of } 17 \\
\text { Students } \\
\end{array}$ \\
\hline \multirow{5}{*}{ The workload was too heavy } & Strongly Disagree & 0 \\
\hline & Disagree & 4 \\
\hline & Neither Disagree nor Agree & 5 \\
\hline & Agree & 3 \\
\hline & Strongly Agree & 5 \\
\hline \multirow{5}{*}{ The workload was too difficult } & Strongly Disagree & 0 \\
\hline & Disagree & 3 \\
\hline & Neither Disagree nor Agree & 6 \\
\hline & Agree & 2 \\
\hline & Strongly Agree & 6 \\
\hline \multirow{5}{*}{ The sessions were well organised } & Strongly Disagree & 0 \\
\hline & Disagree & 0 \\
\hline & Neither Disagree nor Agree & 0 \\
\hline & Agree & 7 \\
\hline & Strongly Agree & 10 \\
\hline \multirow{5}{*}{$\begin{array}{l}\text { Discussions stressed important } \\
\text { aspects }\end{array}$} & Strongly Disagree & 0 \\
\hline & Disagree & 0 \\
\hline & Neither Disagree nor Agree & 2 \\
\hline & Agree & 5 \\
\hline & Strongly Agree & 10 \\
\hline \multirow{5}{*}{ The sessions were enjoyable } & Strongly Disagree & 0 \\
\hline & Disagree & 0 \\
\hline & Neither Disagree nor Agree & 0 \\
\hline & Agree & 5 \\
\hline & Strongly Agree & 12 \\
\hline \multirow{5}{*}{$\begin{array}{l}\text { The sessions were relevant to the } \\
\text { degree being studied }\end{array}$} & Strongly Disagree & 0 \\
\hline & Disagree & 0 \\
\hline & Neither Disagree nor Agree & 1 \\
\hline & Agree & 4 \\
\hline & Strongly Agree & 12 \\
\hline
\end{tabular}

Cohen, L., Manion, L. and Morrison, K. (2000) Research methods in education. 5th ed. London; New York: RoutledgeFalmer, p.446. 
Colbeck, C.L., Campbell, S.E. and Bjorklund, S.A. (2000) Grouping in the Dark: What College Students Learn from Group Projects. The Journal of Higher Education, 71(1), pp. 6083.

Denscombe, M. (2010) The good research guide for small-scale social research projects. Maidenhead, England: McGraw-Hill/Open University Press.

Felder, R.M. and Brent, R. (2005) Understanding student differences. Journal of Engineering Education, 94(1), pp.57-72.

Haddock, J. (1993) Profile of a Nurturing College Professor. Journal of Engineering Education, 82(1), pp.34-37.

Huddleston, P. and Unwin, L. (1997) Teaching and learning in further education. First Edition ed. London; New York: Routledge.

Joham, C. and Clarke, M. (2012) Teaching critical management skills: the role of problembased learning. Teaching in Higher Education, 17(1), pp.75-88.

Loo, R. (2004) Kolb's learning styles and learning preferences: is there a linkage? Educational Psychology, 24(1), pp.99-108.

Oates, B. (2006) Researching information systems and computing. London: SAGE. 